\title{
Algumas abordagens teóricas do espaço urbano e dos processos sócio-espaciais e a contribuição de Lefebvre.
}

\section{Prissilla Mello de Oliveira ${ }^{1}$}

\section{Resumo}

O objetivo deste artigo é destacar a contribuição de Lefebvre para a análise dos processos sócio-espacias urbanos e a importância das representações na teoria crítica do espaço. No entanto, para entender as atuais discussões acerca do espaço urbano é fundamental apresentar a importância, as críticas e as transformações relacionadas as abordagens teóricas e metodológicas marxista, estruturalistas e pós-estruturalistas do espaço urbano e dos processos sócio-espaciais.

Palavras-chave: abordagens teóricas; espaço urbano; representações; Lefebvre.

\section{Abstract}

The aim of this article is to highlight the contribution of Lefebvre for the analysis of social-spatial processes and the importance of urban representations in critical theory of space. However, to understand the current discussions about urban space is crucial to present the importance, the critical and the transformations relating the theoretical and methodological approaches Marxist, structuralist and poststructuralist of urban space and the socio-spatial processes.

Keywords: theoretical; urban space; representations; Lefebvre.

Este artigo tem como objetivo apresentar a contribuição de Lefebvre e das representações na análise do espaço urbano e dos processos sócioespaciais. Neste sentido, faz-se necessário apresentar a importância, as críticas e as transformações relacionadas a algumas abordagens teóricas e metodológicas relacionadas a este tema.

Após a breve apresentação das abordagens marxista, estruturalista e pós estruturalista, que contextualizam as atuais concepções sobre os processos sócio-espaciais, pretende-se apresentar a contribuição de Lefebvre para a análise de tais processos urbanos e a importância das representações na teoria crítica do espaço. 


\section{Algumas abordagens e suas transformações}

Para entender as atuais discussões acerca do espaço urbano é fundamental apresentar algumas concepções de determinas abordagens sobre o tema. Segundo Lefebvre (1991) o papel e o sentido da teoria Marxista era passar para a linguagem, para o conceito e para o sentido as influencias e as capacidades da produção industrial, ou seja, Marx teria enfatizado a produção industrial no capitalismo. Lefebvre (1991) firma que o fenômeno da urbanização (que possui relação direta com a industrialização) era contemporâneo a Marx, sendo complicado para ele compreender toda a sua complexidade e suas consequências futuras. Ou seja, era difícil para Marx perceber e descobrir na "produção do urbano a finalidade, o objetivo e o sentido da produção industrial" (1991:206). Marx analisava de forma dialética o modo de produção capitalista, considerando na forma do valor de troca e da mercadoria o elo principal deste modo de produção. Neste sentido, a mercadoria teria, ao mesmo tempo, uma forma, uma lógica e uma linguagem, pois possuía tanto um caráter destruidor como criador, sendo possível a dominação do mercado e suas leis pela força social. Muitas foram às interpretações equivocadas da obra de Marx. Os marxistas "vulgares" enfatizaram o economismo (relacionado à organização, o planejamento e a racionalidade industrial, muito oportuno à direita) e o politismo (relacionado ao ativismo, as instituições e as ideologias).

Segundo Gottdiener (1997), a análise urbana marxista surgiu em meio a problemas de formulações convencionais sobre os eventos urbanos, principalmente a partir da Segunda Guerra Mundial. Assim como a análise estruturalista marxista surgiu como resposta teórica ao marxismo ortodoxo. A visão da propaganda stalinista e de economistas políticos "vulgares" deram ênfase ao econômico, que seria determinante da política e da cultura, formando então uma idéia de "superestrutura". O que surgiu na contrapartida desta concepção foi a Escola de Frankfurd, que passou a considerar as necessidades culturais e políticas para além da economia. Lukács e Gramsci são citados por Gottdiener (1997) como autores que destacavam que os fenômenos superestruturais poderiam tanto servir para a manutenção do sistema capitalista como para "estimular" sua transformação.

A Escola de Frankfurd, assim como Lukács e Gramsci, buscavam desenvolver análises culturais da sociedade moderna, entendendo o capitalismo como totalidade. Já o marxismo, sob a influencia do estruturalismo, não aceitava a dependência dos fenômenos sociais em relação ao comportamento do sujeito individual. Segundo Gottdiener (1997), Louis Althusser (líder da leitura estruturalista de Marx) preservou a noção de totalidade da Escola de Frankfurd, considerou também a noção de independência dos fatores políticos e ideológicos com relação à base econômica política, mas não focalizou as contradições, dando ênfase a idéia 
de crise básica do capitalismo. O estruturalismo de Althusser visava uma teoria de organização social.

A partir da década de 1980 começam a surgirem críticas as abordagens marxistas e estruturalistas, pois se passou afirmar que as análises macrossociais (e baseados apenas na economia) eram insuficientes para entender a complexidade dos processos sócio-espaciais. A produção do conhecimento começou a sofrer uma crise. Segundo Topalov (1988) (apud Costa 2007) de 1965 até 1988 a crise sobre a leitura do espaço urbano e regional se manifesta em 3 níveis: "o objeto da pesquisa urbana havia se dissipado, as instituições responsáveis por tais pesquisas se esfaleceram e os conceitos teóricos se esgotaram" (2007:1). Topalov afirma, então, que a crise resultou no surgimento de velhos conceitos e teorias, abandonando os fenômenos macrossociais e valorizando a escala do lugar. Costa (2007) vê essas idéias de Topalov como um importante marco nos questionamentos sobre o urbano, estas eram, na verdade, um momento de reflexão (questionamento) sobre o paradigma marxista que dominou a análise urbana por um longo tempo.

A partir das críticas as abordagens marxistas e estruturalistas tradicionais, que estavam restritas a macroestrutura, surgem estudos que valorizam escalas micro. Ocorrem duas situações neste novo contexto: esses novos estudos (também chamados de pós- estruturalistas ou pós-modernistas) enfocam aspectos relevantes da dinâmica sócio-espacial que teriam sido ignorados por perspectivas totalizantes e economicistas do marxismo e estruturalismo. Por outro lado, esses novos estudos (em sua maioria) acabam apresentando resultados fragmentados e parciais da realidade.

Costa (2007) explica que existem três tendências principais para as abordagens teóricas e metodológicas de análises dos processos sócioespaciais: as baseadas na economia política, as interpretações pósestruturalistas e o denominado populismo urbano.

Fainstein (apud Costa 2007:2) afirma que "o fato de a economia política ter como ponto de partida a base econômica representa ao mesmo tempo vantagens e desvantagens". A principal desvantagem é justamente seu ponto de partida (o econômico), pois acaba desconsiderando outros elementos também importantes. Já a concepção pós-estruturalista valoriza a dimensão cultural e do cotidiano, mas em contrapartida ignora a questão econômica e os interesses de classe dos aspectos sócio-espaciais, sendo desta forma reducionista. $O$ foco analítico do populismo urbano tem como valores centrais à democracia e os direitos individuais, mas não é exatamente uma teoria, e sim uma prática. Sinteticamente, o enfoque da economia política estaria ligado ao conceito de igualdade, o pós-estruturalismo ao de diversidade e o populismo urbano ao de democracia. No entanto, os três enfoques são inerentes ao conceito de justiça social. A união desses três enfoques poderia ser, segundo 
Costa (2007), uma saída para a possível crise na produção do conhecimento.

Como alternativa para a análise dos processos sócio-espaciais, Gottdiener (1997) apresenta um importante diálogo entre Castells e Lefebvre, demonstrando as diferenças e possíveis semelhanças entre esses autores marxistas no que diz respeito as suas concepções sobre o espaço urbano. Alem de apresentar a contribuição de ambos para a produção do conhecimento.

Para Castells (discípulo de Althusser) todos os sistemas estruturais possuem em seu âmago subsistemas de práticas homogêneas ligadas a estrutura maior, pois atuam segundo as mesmas leis. Entende-se, neste sentido, o urbano como um subsistema único. Castells fez avançar (segundo Gottdiener 1997) a análise urbana marxista. Posto que, ele criticou a ciência urbana convencional (espacialmente a sociologia); deu ao estudo da política urbana e de movimentos sociais uma estrutura marxista; alem de ter estabelecido uma relação teórica entre o conceito de urbano com a concepção marxista do Estado. No entanto, Castells corrobora com a idéia de que não existe uma teoria específica do espaço, mas sim uma maior complexidade da estrutura social. Ele entende o espaço como a materialidade de uma dada formação social, sendo um tipo de "anexo" da teoria da estrutura social. Ele busca, então, explicar teoricamente o que entende por urbano. Destaca então dois elementos fundamentais da estrutura econômica: os meios de produção e a força de trabalho. Castells define o urbano como "uma unidade espacial dentro do sistema estrutural que produz o ambiente construído" (apud Gottdiener 1997: 123).

Já Lefebvre (segundo Gottdiener 1997) dá grande importância à "práxis espacial", que está ao lado de esforços para reorganizar as relações sociais. O espaço para Lefebvre possui uma natureza multifacetada, pois representa uma multiplicidade de preocupações sócio-materiais, não sendo possível reduzi-lo a uma localização ou as relações sociais de posse da propriedade. Lefebvre não reduz o espaço aos três domínios da economia política marxista: produção, consumo e troca. Para ele há um quarto domínio: a produção de riqueza ou de mais valia. A introdução da dimensão política da questão do espaço é o que o diferencia da tradicional economia política. Lefebvre afirma que a sociedade se reproduz, em parte, por meio do espaço. Então, o capitalismo sobrevive, em parte, por meio do controle do espaço. Sendo não apenas uma força e meio de produção, mas também um produto. Para Lefebvre o conflito resultante dos antagonismos espaciais vai para alem das questões de classe, pois não é fruto, apenas, das relações de produção. Ele afirma que o pensamento marxista não deve ficar restrito ao fator econômico, eis ai um dos motivos de muitas críticas a sua obra pelos marxistas ortodoxos. É em contrapartida, um importante elemento para o avanço da teoria social crítica. Segundo Costa (2007), Lefebvre tem uma essência de argumentação sobre a produção do espaço bastante clara e coerente. Ele é complexo, mas apresenta uma clara proposta de uma teoria única para o 
espaço, para tanto ele utiliza o método dialético.

Percebe-se que uma das coisas que diferencia Castells de Lefebvre é que para o primeiro existe uma complexificação da teoria da estrutura social, e não uma teoria específica do espaço, ao contrário do que afirma Lefebvre.

Assim, em oposição a Lefebvre, que desenvolveu uma teoria marxista do espaço a fim de moldar o que ele denomina uma práxis sócio- espacial, Castells deseja afirmar o primado da teoria althusseriana da estrutura social, que então pode ser usada para explicar as formas espaciais. (GOTTDIENER, 1997:120)

Apesar de Castells e Lefebvre possuírem concepções diferentes, ambos fornecem alternativas para o pensamento marxista, muito voltado para a análise do espaço. Ambos possuem uma concepção mais global da articulação entre sociedade e espaço, mesmo empregando epistemologias diferentes.

\section{O papel das representações na teoria crítica do espaço}

Lefebvre (1991) não restringe o espaço urbano ao aspecto econômico da produção, pois considera também o cotidiano da vida nas cidades. Para Lefebvre, o espaço urbano é um mediador, ou seja, tanto é produzido pela sociedade como influencia na sua produção. É fruto de contradições, posto que possui intencionalidade, não é neutro e está em constante construção. Para Lefebvre, segundo LUFTI et all (1996), a revolução passa pela subjetividade, pela práxis criadora e pela vida cotidiana.

Neste sentido, Lefebvre (1991) divide didaticamente o espaço social em três dimensões: as práticas espaciais, as representações do espaço e os espaços de representações ou espaço percebido, concebido e vivido. Neste sentido, a prática espacial está diretamente ligada à experiência, ao domínio da percepção física (sensações). É então o espaço percebido. Está relacionado à realidade do dia-a-dia (cotidiano) e a realidade urbana. Há nela uma relação paradoxal que envolve as várias escalas da produção e reprodução do capital. $A$ representação do espaço está diretamente relacionada ao espaço concebido, ou seja, é o espaço gerado pelos cientistas, planejadores, urbanistas, tecnocratas, engenheiros, etc. É o espaço dominante em qualquer sociedade (ou meio de produção), pois tem relação intrínseca com o domínio dos conhecimentos técnicos, dos códigos hegemônicos, conseguentemente do poder. Já o espaço de representação é o espaço diretamente vivido através da associação de imagens e símbolos. É o espaço dominado pelas sensações, 
pela imaginação, pela emoção, pelos significados, onde esses elementos são incorporados ao viver diário. É nesta dimensão em que a verdadeira contestação pode ganhar terreno. Esses espaços de representação são "parcelas" da forma como vivemos no mundo, eles envolvem nossa vida cotidiana, da mesma forma que afeta diretamente as experiências e as formas como entendemos e interpretamos as representações.

Estas três categorias de espaço apresentadas por Lefebvre (1991) estão hierarquicamente organizadas, mas elas devem ser entendidas em uma relação dialética. Já que na realidade elas ocorrem juntas. Por exemplo, na rotina diária das práticas espaciais nós observamos uma certa noção de representação espacial que nos permite construir espaços de representações próprios.

Percebe-se que a questão da representação está presente na obra de Lefebvre, tanto que ele se dedica a discussão sobre a contribuição da teoria das representações em seu livro: "La presencia y la ausência. Contribución a la teoria de las representaciones" (1983).

Segundo LUFTI et all (1996) o conhecimento não deve ser encarado como uma verdade absoluta (imutável). Para Lefebvre o objeto do conhecimento vai se construindo, sendo necessário entender seu espaço e seu tempo no processo de conhecer. O seu método é uma "possibilidade de conceber as virtualidades do objeto" (LUFTI et all 1996:88). Lefebvre se preocupa com o que bloqueia e com o que libera o processo histórico. Por este ponto de vista afirma que "as representações como mediações se constroem como objeto do conhecimento". E "que o que se representa está presente e ausente, ao mesmo tempo, na representação" (1996:88). Ou seja, a ausência é medida pela presença e vice-versa, elas não se excluem. Lefebvre investiga a importância e o lugar das representações na sociedade contemporânea, destacando que as representações podem ser ao mesmo tempo falsas e verdadeiras, e que esta ambigüidade lhes dá poder.

Algumas representações são engendradas pelas relações e pelo modo de produção e se colocam a serviço de ambos. Outras representações vem de sociedades anteriores, de mitologias, de religiões. Todas se elaboram em ideologia e cientificidade e podem ser bastante modificadas. Lefebvre propõe, então, "desvendar as formas de substituição e deslocamento que ocorrem nos processos de representação", contribuindo para uma teoria crítica das representações (1996: 90).

Lefebvre (apud LUFTi et all 1996) faz uma reconstrução da trajetória do conceito de representação na filosofia. Primeiramente cita Kant, para o qual o mundo sensível e percebido é um mundo de representações. Kant traz a possibilidade de pensar a representação como conhecimento. Lefebvre menciona também Hegel, para este filósofo a representação é uma etapa, um momento do conhecimento. Hegel formula uma concepção de dialética de representação, onde a representação deve ser superada. Já Marx também trabalha com o conceito de representação, mas acaba substituindo-o pelo

TAMOIOS. ANO V. № 1, 2009 - ISSN 1980-4490 
conceito de ideologia. O termo ideologia é utilizado por Marx com uma conotação negativa, ele encara as ideologias como mentiras de classe, propondo sua superação através da revolução.

Lefebvre (apud LUFTI 1996) propõe a utilização dessas duas noções (ideologia e representação), ele afirma que ao ficar restrito a ideologia há uma desconsideração do vivido, valorizando apenas o concebido. Mas que é fundamental compreender que a ideologia tem sua gênese no vivido e que a representação engloba a ideologia, sendo um conceito mais amplo. Ele explica, então, que a sociedade contemporânea tem a capacidade de perpetuar as representações, e que isso não teria sido previsto por Marx. Por fim, Lefebvre vai a Nietzsche para discutir como a linguagem nasce socialmente e pode transmitir opiniões e representações. Ela (a linguagem) pode resultar em mentiras ou verdades, posto que surge na prática social, na luta pelo poder. Nietzsche desenvolveu a idéia da representação relacionada a sentimentos, a paixões, vontades e pontos de vista. Ou seja, representar resulta numa valorização (negativa ou positiva). Para que algo tenha valor é necessário estar representado, mas atribuir valor transforma a representação.

Lufti et all (2006) destaca que Lefebvre utilizou cada um desses autores anteriormente mencionados para construir sua teoria da representação.

Ao construir sua teoria da representação, Lefebvre atualiza momentos decisivos do trabalho de seus antecessores: de Kant, a representação como conhecimento, de Hegel, o movimento dialético do pensamento, de Marx, a reviravolta materialista e a possibilidade de desvendamento de ideologias representações e, finalmente, de Nietzsche, os sentimentos e o valor como elementos constitutivos da representação que vai buscar. (1996:94)

Lefebvre deixa claro que as representações produzem imagens de determinados povos, classes, e etc. Elas são produtos de um determinado processo social. Está diretamente ligada ao problema da dominação e da exploração, pois através dela pode-se difundir imagens que perpetuem a dominação, sem necessariamente mentir. Lefebvre tratou, então, as representações como mediação, sendo uma dimensão do vivido e fatos da prática social. 


\section{Considerações finais}

A análise do espaço urbano e dos processos sócio-espaciais passou por diversas transformações. Percebe-se que a valorização restrita do aspecto econômico voltada apenas para a macroestrutura não é suficiente para entender a complexidade dos processos sócio- espaciais. Assim como a ênfase restrita a escala do cotidiano e das especificidades locais também não é. É fundamental utilizar abordagens que levem em consideração esses aspectos de forma mais ampla.

Apresentamos aqui algumas abordagens do espaço urbano e suas respectivas críticas. Destacando a necessidade de não descartar as concepções anteriores, mas sim aproveitá-las na análise. Neste sentido, apontamos a contribuição de Lefebvre para a análise do espaço urbano.

Lefebvre cria uma teoria específica para o espaço que contribui significativamente para a análise dos processos sócio-espacias urbanos. Ele considera tanto os aspectos da macro como da micro estrutura e demonstra a importância das representações na teoria crítica do espaço.

\section{Notas}

1- Mestranda em Geografia e Meio Ambiente pela Pontífice Universidade Católica do Rio de Janeiro. Pós graduação (latos senso) em ensino de Geografia e Graduação em Geografia pela Universidade do Estado do Rio de Janeiro / FFP.

\section{Referencias bibliográficas}

COSTA, Geraldo Magela. Teorias sócio-espaciais: diante de um impasse? Etc..., espaço, tempo e crítica. Revista Eletrônica de Ciências Humanas e Sociais - http://www.uff.br/etc, n. 2 (2), vol. 1, p. 1- 11, Julho de 2007.

GOTTDIENER, Mark. Paradigmas flutuantes: o debate sobre a teoria do espaço. In GOTTDIENER, Mark. A produção social do espaço urbano. 2.ed. São Paulo: Edusp, 1997.

Além de economia política marxista: a formula da trindade e a analise do espaço. In GOTTDIENER, Mark. A produção social do espaço urbano. 2.ed. São Paulo: Edusp, 1997. 
LEFEBVRE, Henri. A vida cotidiana no mundo moderno. São Paulo: Ática, 1991. Plan of the present work. In. LEFEBVRE, Henri. The production of space. Oxford, UK: Blackwell, 1991.

LUFTI, Eulina Pacheco, SOCHACZEWSKI, Suzanna, JAHNEL, Teresa Cabral. As representações e o possível. In MARTINS, José de Souza (org.) Henri Lefebvre e o retorno à dialética. São Paulo: Hucitec, 1996. 